\title{
KONFLIK MASYARAKAT BATAK TOBA KEPADA PT. INTI INDORAYON UTAMA DI DESA SIRAIT-URUK KEC. PORSEA KAB. TOBA SAMOSIR TAHUN (1983-2004)
}

\author{
Oleh: \\ Tappil Rambe \\ Andi Putra Manurung
}

\begin{abstract}
ABSTRAK
Tujuan penelitian ini adalah: (1) Untuk mengetahui arti tanah dan kehadiran PT.Inti Indorayon Utama bagi kehidupan masyarakat Batak Toba di Desa Sirait-Uruk Kec. Porsea Kab. Toba Samosir. (2) Untuk mengetahui perlawanan masyarakat Batak Toba kepada PT.Inti Indorayon Utama di Desa Sirait-Uruk Kec.Porsea Kab Toba Samosir Tahun 1983-2004. (3). Untuk mengetahui dampak dari perlawanan masyarakat kepada PT. Inti Indorayon Utama. Penelitian ini menggunakan metode penelitian lapangan (Field Research) untuk mengumpulkan data dari lapangan dan metode studi pustaka (Library Research) untuk memberikan penjelasan menurut sumber-sumber yang berkaitan. Teknik pengumpulan pada penelitian ini menggunakan teknik observasi untuk meninjau lokasi dari peristiwa perlawanan masyarakat Batak Toba, wawancara untuk mendapat informasi secara mendalam tentang penelitian dan studi pustaka untuk melengkapi sumber dari buku dan literatur yang terkait dengan penelitian.Hasil penelitian yang diperoleh adalah: (1) mengetahui arti tanah bagi masyarakat Batak Toba dan sejarah kehadiran dari PT. Inti Indorayon di Porsea. (2) mengetahui perlawanan masyarakat Batak Toba kepada PT. Inti Indorayon Utama, baik dari kronologis perlawanan, bentuk perlawanan dan keterlibatan pihak-pihak lain dalam perlawanan masyarakat Batak Toba tersebut. (3) mengetahui dampak atas perlawanan masyarakat Batak Toba kepada PT. Inti Indorayon Utama bagi masyarakat Batak Toba khususnya bagi Desa Sirait-Uruk.
\end{abstract}

Kata Kunci : Konflik, Batak, Indorayon. 


\section{I.PENDAHULUAN}

Semasa Orde Baru, Pembangunan adalah segalanya,rakyat tidak berdaya menolak pembangunan, walau dengan pembangunan itu mereka tergusur dan mati. Ada banyak kelompok adat yang berjuang membela haknya, yang dirampas oleh sang dewa pembangunan seperti, di Kalimantan, Jawa, Papua, NTT, Jambi, Lampung, Aceh dan daerah-daerah lain. Intinya dari Sabang sampai Merauke berjejer kelompok rakyat yang semakin miskin digilas roda pembangunan dalam Saur Situmorang (2010:1)

Dengan banyaknya pengalaman pahit dari rakyat dalam menghadapi proses terjadinya pembangunan membuat gambaran dari pembangunan bagi banyak masyarakat identik dengan sengketa dan perkara. Tak dapat dipungkiri, memang seperti itulah realita yang ditemukan di lapagan.

Di Toba Samosir, lebih khusus lagi Desa Sirait-uruk, Kecamatan Porsea, Kabupaten Toba Samosir, Provinsi Sumatera Utara. Sirait-uruk adalah sebuah desa kecil berpenduduk sekitar 3.000 jiwa yang terletak $215 \mathrm{~km}$ di selatan Medan, ibu kota provinsi Sumatera Utara, berdiri sebuah perusahaan bernama PT. Inti Indorayon Utama (PT.IIU) adalah sebuah pabrik yang memproduksi pulp (bubur kertas) dan rayon (bahan untuk membuat serat kain) dalam Edison Hasibuan (2000:29).

PT.IIU yang memang sejak kemunculannya pada tahun 1983 ditengahtengah masyarakat Porsea telah menimbulkan banyak kontroversi dan tantangan protes yang sangat tajam dari rakyat. Dimana penolakan ini didasari atas ketakutan masyarakat akan bahaya yang ditimbulkan oleh Indorayon terhadap lingkungan hidup dan ekonomi masyarakat. Dilanjutkan dengan masalah sebuah pabrik penghasil bubur kertas ini dapat membuat empat preside indonesia ; mulai dari Soeharto, BJ Habibie, Abdurrahman Wahid sampai Megawati Soekarno Putri kerepotan mengurusinya bahkan sampai hari ini juga aktivitas produksi pulp oleh pabrik ini masih berlangsung walaupun dengan menggunakan nama barunya yang dikenal masyarakat dengan sebutan PT.TPL.

Di berbagai desa dan daerah muncul perlawanan, diantaranya perlawanan kaum ibu-ibu atau inang-inang par air kamis didesa sugapa atas perampasan tanah 
adat mereka. Dilanjutkan dengan longsornya bukit di Desa Sigumpar II yang membuat 13 nyawa melayang hingga sampai hebohnya masyarakat Porsea akibat pecahnya limbah cair Indorayon dan berbagai kasus lainya yang menyebabkan perlawanan yang sangat keras dari masyarakat terhadap pihak pabrik secara terus menerus

Dengan rangkaian kasus dan peristiwa akibat kehadiran indorayon di tanah tapanuli ini membuat rakyat porsea semakin gencar untuk melakukan perlawanan walaupun disetiap terjadinya perlawanan selalu menjatuhkan korban sampai dengan kasus kematian dari seorang mahasiswa UI bernama Panuju Manurung dan Siswa SMK bernama Hermanto seperti yang terdapat pada Saur Situmorang (2010:2-6).

Rakyat Porsea yang mendapat dukungan dari berbagai kalangan di tingkat lokal, nasional, bahkan sampai luar negeri tetap gigih berjuang dan menolak menjadi miskin atas kehadiran pabrik Indorayon di daerah mereka, hal ini terjadi karena sebelum kedatangan Indorayon dan melakukan aktifitas produksinya, kehidupan masyarakat Porsea relatif tentram dan sejahtera. Apapun mereka usahakan, baik mulai dari bersawah, memelihara ikan setelah selesai proses memanen padi di sawah atau juga beternak ayam, babi, kerbau dan sapi yang selalu dapat memberikan hasil yang menggembirakan.

Metode penelitian merupakan aturan sistematis yang berguna sebagai proses dalam memperoleh fakta-fakta dan prinsip-prinsip untuk mencari kebenaran dari permasalahan. Metode yang penulis pergunakan dalam melakukan penelitian ini adalah metode sejarah. Adapun tahapannya ialah sebagai berikut : Heuristik merupakan kegiatan mencari sumber-sumber untuk mendapatkan data-data atau materi sejarah atau evidensi sejarah bertujuan untuk menjadikan sumber-sumber mana yang lebih tepat untuk dijadikan sumber sejarah dalam penelitian penulis. Kemudian Kritik sumber yang dilakukan peneliti berfungsi untuk menyaring datadata yang memang benar sejalan dengan keterangan-keterangan yang terdapat dalam sumber sejarah. Data-data yang terkumpul diseleksi dan dikritisi guna memperoleh fakta yang teruji. 


\section{PEMBAHASAN}

Seperti yang sudah dibahas dalam pendahuluan, dalam kasus perlawanan masyarakat Batak Toba kepada PT. Inti Indorayon Utama merupakan sebuah kasus perlawanan yang panjang. Kasus yang sudah dimulai sejak tahun 1983 ini adalah pembuktian bahwa rakyat yang tidak dapat berdaya melawan sebuah kekuasaan.

Perlawanan yang dilakukan oleh masyarakat Batak Toba kepada PT. Inti Indorayon Utama dilatarbelakangi karena masyarakat yang merasa terancam atas kehadiran dari pabrik Indorayon ini. Beberapa contohnya, masyarakat tidak bisa menerima tanah mereka dikuasai oleh pihak pabrik, hutan-hutan mereka dijadikan sebagai lahan untuk bahan utama yang diproduksi pabrik. Dalam kasus tanah inilah menjadi awal ketidak nyamanan masyarakat karena mereka tidak mendapat ganti rugi atas tanah mereka yang direbut oleh pabrik dengan bantuan yang dilakukan oleh pemerintah.

Selain itu, masyarakat melawan karena kehidupan ekonomi mereka yang dulunya bisa dikatakan cukup sejahtera dari hasil pertanian dan perikanan terancam hancur karena limbah yang dikeluarkan oleh pabrik. Jadi alasan-alasan belakang perlawanan masyarakat Batak Toba kepada Pihak Pabrik Indorayon.

Perlawanan-perlawanan yang dilakukan oleh masyarakat kepada pihak pabrik dimulai dari perlawanan bersifat lokal. Dimana mereka melakukan perlawnan dengan melakukan aksi protes dan juga melakukan tuntutan hukum kepada pengadilan atas ketidak adilan yang mereka dapatkan akibat kehadiran PT. Inti Indorayon Utama ini. Selanjutnya, perlawanan masyarakat yang tidak mendapatkan titik terang atas segala tuntutan mereka. Perlawanan masyarakat berlanjut dengan meluaskan aksi protes dengan bantuan yang dilakukan oleh beberapa organisasi non-pemerintah yang melakukan bimbingan kepada masyarakat untuk melakukan tuntutan kepada masyarakat.

Tetapi, segala aksi masyarakat seakan-akan tidak mendapatkan hasil. Masyarakat diberikan harapan-harapan yang tidak pasti. Memang benar jika pemerintah beberapa kali menjawab tuntutan masyarakat tetapi selalu berubah karena pabrik Indorayon tetap bisa berdiri dan berproduksi. 
Khususnya, dalam setiap aksi protes masyarakat melawan selalu mendapat hadangan dari pihak aparat keamanan. Tidak sedikit masyarakat yang menjadi korban atas aksi kekerasan yang dilakukan oleh pihak keamanan. Para korban banyak yang terluka, beberapa yang menjadi korban meninggal dan korban lainnya.

Tidak hanya itu, dari kasus ini juga memberikan dampak yang banyak terhadap kehidupan sosial masyarakat. Mulai dari rusaknya hubungan sosial masyarakat dengan terpecahnya masyarakat menjadi 2 kubu yang mendukung pabrik dan melawan pabrik.

Dan pada akhirnya, tahun 2000-an perlawanan masyarakat mulai berakhir. Masyarakat sudah berhenti menuntut karena menganggap bahwa mereka melakukan hal yang sia-sia yang pada akhirnya akan merugikan mereka semua.

\section{PENUTUP}

Dengan berdirinya pabrik PT.Inti Indorayon Utama, banyak kontroversi yang ditimbulkan dan semuanya merungikan masyarakat begitu juga dengan negara. Salah satunya Indorayon yang bisa dengan mudahnya mendirikan pabrik dan mendapatkan lahan yang luas untuk kepentingan pabrik tampa diketahui oleh masyarakat yang berada disekitar Indorayon. Indorayon yang berproduksi dalam bidang pulp dan rayon ini dianggap menjadi ancaman bagi masyarakat. Selain Indorayon yang telah secara semenah-menah mengambil tanah rakyat/tanah ulayat. Indorayon juga dianggap tidak aman dalam proses produksinya karena memakai bahan kimia yang sangat berbahaya jika tencemar ke lingkungan. Apalagi, posisi Indorayon dibangun berada di hilir sungai Asahan yang menjadi salah satu aliran untuk kehidupan pertanian rakyat dan beberapa usaha lain.

Akibat tindakan Indorayon yang dianggap membahayakan kehidupan masyarakat, khususnya masyarakat sekitar pabrik (Porsea dan sekitarnya). Masyarakat melawan dan melakukan aksi protes agar Indorayon ditutup karena membahayakan kehidupan masyarakat akibat dampak lingkungan yang ditimbulkan. Perlawanan-perlawanan masyarakat inilah yang memperlemah kedudukan Indorayon dan mengancam bahwa pabrik tidak dapat berproduksi. Masyarakat yang melawan melakukan segala upaya agar Indorayon benar-benar 
ditutup. Mulai dari aksi protes kepada pihak pabrik dan pemerintah, melalui jalur diskusi dengan pemerintah, aksi penutupan jalan dan penghadangan kepada yang bersangkutan kepada pa brik, aksi damai melalui ibadah dan bentuk perlawanan lain yang bisa melemahkan kedudukan Indorayon, agar pabrik ini benar-benar ditutup dan masyarakat bisa hidup tenang tampa ancaman yang ditimbulkan oleh pabrik.

Perlawanan masyarakat bukanlah sekedar perlawanan yang bersifat lokal saja. Dalam setiap perlawanan masyarakat yang awalnya memang hanya berada di daerah sekitar pabrik, dapat meluas karena masalah yang terjadi di Porsea menarik perhatian dari masyarakat di luar Porsea yang mengatas namakan membela kepentingan rakyat dan kepentingan lingkungan. Sedikit demi sedikit perlawanan rakyat membesar dengan bantuan dari aktivis-aktivis yang berjuang membela rakyat. Beberapa organisasi non-pemerintah rela membela dan membantu masyarakat agar keinginan masyarakat atas masalah Indorayon bisa di selesaikan secepatmungkinbaik melalui tindakan apapun.

Kehadiran Indorayon di daerah Porsea yang menciptakan sebuah gerakan sosial ini memberikan kerugian kepada masyarakat melalui limbah dan kekerasan yang ditimbulkan. Perlawanan yang dilakukan masyarakat juga memberikan kerugian kepada masyarakat yang melawan Indorayon itu sendiri. Mulai dari habisnya tenaga, waktu dan pikiran masyarakat akibat melawan dan menuntut agar Indorayon berhenti dan ditutup, begitu juga untuk pemerintah yang selalu membela Indorayon. Selain itu, masyarakat juga dirugikan dengan hilangnya nyawa dari beberapa orang yang ikut dalam beberapa aksi, hal ini bisa terjadi diakibatkan pihak pabrik yang dibantu oleh aparat keamanan yang tidak segan-segan melakukan tindakan kekerasan jika terjadi benturan disaat setiap aksi masyarakat menuntut Indorayon untuk ditutup.

Hingga pada akhirnya, masyarakat merasakan hasil dari usaha dan kerja keras mereka untuk menutup Indorayon, masyarakat merasa senang dengan ditutupnya pabrik Indorayon ini. Tetapi penutupan Indorayon hanya terjadi dalam beberapa tahun saja. Dengan segala cara, Indorayon membuat masyarakat kembali kecewa dengan dibukanya kembali pabrik dan diperbolehkan untuk beroperasi 
kembali. Indorayon yang mendapatkan hak untuk beroperasi kembali membuat sebuah paradigma baru dengan mengubah nama pabrik dan membuat pabrik mereka menjadi Objek Vital Nasional (OVN) yang secara otomatis jika diganggu akan berhadapan dengan pemerintah secara langsung. Dengan perubahan status Indorayon ini membuat masyarakat kembali dikecewakan, tetapi apa daya mereka tidak bisa melawan lagi karena diangap akan sia-sia karena pemerintah akan selalu membantu mereka.

Dari hal inilah hingga saat ini, walaupun hingga saat ini pabrik masih memberikan dampak yang masih merungikan masyarakat. Tidak pernah ada lagi perlawanan yang dilakukan oleh masyarakat dan membiarkan pabrik berdiri dan beroperasi tampa diganggu lagi dengan aksi-aksi protes dari masyarakat.

\section{Referensi}

Abdul (2003) Contetious Politics in Toba Samosir : The Toba Batak Movement Opposing The PT.Inti Indorayon Utama Pulp and Rayon in Sosor LadangIndonesia (1983-2000). Hawai :Universitas Ohio.

Daliman, A.(2012) Metode Penelitian Sejarah. Yogyakarta : Ombak.

Hidayat (2013)Teori Sosial Modern dan PosModern. Medan :Unimed Press.

Hikam, M.A.S (1990) Perlawanan Sosial : Telaah Teoritis dan Beberapa Studi Kasus. Jakarta : LP3ES.

Kusuma, Nur dan Fitria Agustina,ed (2003) Gelombang Perlawanan Rakyat, Kasus Kasus Gerakan Sosial di Indonesia, Yogyakarta : Insist Press.

Mas'oed, Moctar (1998) Tantangan terhadap Integrasi Bangsa, Studi Kasus Konflik Sosial dan Kerusuhan Massa. Yogyakarta : Makalah UGM.

Ritzer, George (2000) Sociological Theory, Fifth Edition. Universityof Maryland.

Sangaji, Arianto (2000) PLTA Lore Lindu :Orang Linduk menolak Pindah. Yogyakarta : Pustaka Pelajar.

Saur.Dkk(2010)Orang-Orang Yang Dipaksa Kalah ; Penguasa dan Aparat Keamanan Milik Siapa? . Jakarta : Yayasan Obor.

Scott, James. C (1981) Moral ekonomi Petani, Pergolakan dan Subsitensi di Asia Tenggara.Jakarta : LP3ES.

Sihbudi, Riza dan Moch.Nurhasim,ed (2001) Kerusuhan Sosial di Indonesia, Studi Kasus Kupang,Mataram dan Sambas . Jakarta : Grasindo.

Simanjuntak, Bungaran (2015) Arti dan Fungsi Tanah Bagi Masyarakat Batak. Jakarta : Yayayasan Pustaka Obor Indonesia.

Soed, Bambang (2003) NGO di Sumut Tolak Beroperasi Kembali Indorayon. Jakarta : Koran Tempo.

Tarrow, Sidney (1994) Power in Movemen, Social Movement, collerctive Action and Politics . Cornell University. 